\title{
Contributions of body fat, fat free mass and arm muscle area in athletic performance of wheelchair basketball players
}

\author{
Lúcia Oliveira $^{1}$, Saulo Oliveira ${ }^{1 *}$, Fernando Guimarães ${ }^{1}$, Manoel Costa ${ }^{1}$
}

ORIGINAL ARTICLE

\begin{abstract}
The aims of this study were: to verify the relationship (1) and dependency (2) between body fat $(B F)$, fat free mass $(F F M)$ and the arm muscle area $(A M A)$ with athletic performance of wheelchair basketball players. Twenty-two subjects were evaluated according to the following order, in 24-hour intervals: a) anthropometric measurements and the Wingate anaerobic test (day 1); b) assessment of $\mathrm{VO}_{2 \text { peak }}$ and threshold (2); and c) specific tests (3). The results showed satisfactory relationships of AMA with handgrip left $(\mathrm{r}=.36 ; \mathrm{p}=.08), \mathrm{VO}_{\text {2peak }}(\mathrm{r}=.59 ; \mathrm{p}=.03)$, medicine ball throwing $(\mathrm{r}=.54 ; \mathrm{p}=.00)$, absolute $(\mathrm{r}=.61$; $\mathrm{p}=.00)$ and relative anaerobic power $(\mathrm{r}=.67 ; \mathrm{p}=.00)$. BF with handgrip left $(\mathrm{r}=.43 ; \mathrm{p}=.03)$, medicine ball throwing $(\mathrm{r}=.50 ; \mathrm{p}=.01)$, absolute $(\mathrm{r}=.77 ; \mathrm{p}=.00)$ and relative $(\mathrm{r}=.82 ; \mathrm{p}=.00)$ anaerobic power. And FFM with handgrip $(\mathrm{r}=.44 ; \mathrm{p}=.03)$, medicine ball throwing $(\mathrm{r}=.43 ; \mathrm{p}=.03)$, absolute $(\mathrm{r}=.64 ; \mathrm{p}=.00)$ and relative $(\mathrm{r}=.69 ; \mathrm{p}=.00)$ anaerobic power. The regression analyses revealed that only predictive models by $A M A$ presented good determination coefficients to $\mathrm{VO}_{2 \text { peak }}\left(\mathrm{r}^{2}=.35 ; \mathrm{p}=.00\right)$, medicine ball throwing $\left(\mathrm{r}^{2}=.29\right.$; $\mathrm{p}=.00)$, absolute $\left(\mathrm{r}^{2}=.37 ; \mathrm{p}=.00\right)$ and relative $\left(\mathrm{r}^{2}=.46 ; \mathrm{p}=.00\right)$ anaerobic Power. The results indicated the importance to consider some anthropometric measures, in particular muscular tissue, to sport training and athletic performance evaluation of wheelchair basketball players.

Keywords: disabled persons, athletic performance, physical fitness, body composition.
\end{abstract}

\section{INTRODUCTION}

Wheelchair basketball is considered one of the precursors of the Paralympic Movement. It is a modality that contains various types of athletes with different disabilities, but which are equivalent in terms of functionality through its classification system. Currently, its regulation occurs through of the International Wheelchair Basketball Federation (IWBF). Its rules are managed by the IWBF in all competitions, whether national or international. The rules of wheelchair basketball, if compared to the standard basketball, has a few changes. In wheelchair Basketball, the wheelchairs have their camber (wheel axle) amended for greater stability on the court. Because of this, they generate a better athletic performance and safer throwing and dribbling. In adapted sport, there is also a classification of athletes due to the functional disparity between them. The functional classification of wheelchair basketball athletes is well defined by people with spinal cord injury or similar disabilities. They are classified in 1.0, 1.5,
$2.0,2.5,3.0,3.5,4.0,4.5$, where the lowest numbers refer to minor functionality.

Wheelchair basketball requires a performance survey from the athletes through collected and data analysis appropriate. However, as the performance is related to many factors such as technical support, biomechanics and physiologic parameters (Goosey-Tolfrey, 2010; Laferrier et al., 2012). Among the criteria used to evaluate and control sessions of training, aerobic capacity and anaerobic are chosen because of its strong relationship with the energy demands of the sport (Flores, de Campos, Gouveia, de Souza Pena, \& Gorla, 2013; Goosey-Tolfrey, \& Tolfrey, 2008;. Vanlandewijck, Van De Vliet, Verellen, \& Theisen, 2006;), as well as specific skills tests commonly used by athletes on the court (Vanlandevijck, Daly, \&Theisen, 1999).

Therefore, the body composition analysis of athletes is an important factor to evaluate and control the physical fitness, measuring the practices and reliably lean mass of those individuals (Goosey-Tolfrey, 2005; Goosey-

Manuscript received at February $2^{\text {nd }} 2016$; Accepted at January $1^{\text {st }} 2017$

${ }^{1}$ Universidade de Pernambuco, Recife, Brasil. Escola Superior de Educação Física, ESEF, Brasil.

* Corresponding author: Universidade de Pernambuco, Rua Arnóbio Marques, 310, Santo Amaro, RecifePernambuco, Brasil. E-mail: saulofmoliveira@gmail.com 
Tolfrey \& Leicht, 2013; Goosey-Tolfrey, \& Tolfrey, 2008;). In this sense, Neto and Lopes (2011) enforce that body composition evaluation is a way to analyze the distribution of different tissues, organs and components responsible for determining the ratio of lean and fat body mass, which are predictive variables for physiological answers to training.

Thus, the importance of studying the link between body composition and performance, comes from the lack of evidence about athletes with disability, which is still wide. According to Mello and Winckler (2012) the variety of deficiencies in adapted sports generates a lack of standard reference and develops defined studies. Knowing these difficulties our aim is to relate the lean mass of wheelchair basketball players in athletic performance variables commonly used for performance evaluation in sport. Being an intermittent sport, wheelchair basketball players usually need a physical training that provides stimulus and enhanced aerobic and anaerobic capacities, as well as muscle power (Davis \& Shephard, 1990; Granados et al, 2015; Noreau, Shephard, Simard, Paré, \& Pomerleau, 1993;).

Previous studies have shown that there are relative contributions to the diverse body components in athletic performance. Among the components, the fat free mass (muscle mass) represents the metabolic active tissue which by muscle contractions can provide the locomotion and physical performance. From the proposed methods to quantify the muscular component, the arm muscle area (AMA) has been utilized because it presents strong relation to the sport performance (Moura, et al., 2014; Santos, et al, 2014). Nevertheless, it is not well known what the relative contributions are, and neither the existent associations between the muscle mass and the athletic performance in wheelchair basketball players.

Referring to people with disability, especially those who utilize wheelchairs, the AMA seems to be more recommended because it focuses only on anthropometric measures of the non-injured limb. From point of view of sports performance in wheelchair basketball, studies have shown that physical fitness tests as well as assessment protocols through specific skills of the sport can be sensitive for comparison class teams and different performance levels (Barfield \& Malone, 2012; Rhodes, Mason, Malone, \& GooseyTolfrey, 2015). It is noted that the specific functional classification seems to influence in a significant way the performance of the sport athletes in general and specific tests of sport (Molik et al., 2014; Molik, Laskin, Kosmol, Skucas, \& Bida, 2010). However, the influence of anthropometric characteristics or body composition on athletic performance basketball players in wheelchairs has not yet been properly studied.

Therefore, knowing the paradigm of locomotion in wheelchair users, and the importance of body composition to sport performance, the aim of the present study was: a) to verify the relationship between the body composition and physical performance in wheelchair basketball players. And b) additionally, we propose the quantification of the degree in athletic performance by muscle mass and percent body fat.

\section{METHODS}

\section{Cross-sectional design}

This research was conducted in three phases and is properly registered with the Ethics Committee of the University of Pernambuco/Brazil (register 078/2011). In the first, subjects were conducted and properly oriented about the procedures that would be performed in steps. Then had their actual anthropometric profile in a standard way by a single trained investigator. Body mass was collected by means of a mechanical scale (Filizola, BRA) with a precision of 100 grams. Even at this stage, engines tests were performed related to anaerobic capacity (Wingate). In the second phase, it was conducted a cardiorespiratory evaluation protocol through open circuit spirometry, direct verification of the volume of exhaled gases. In the third and final stage, field tests were conducted to check agility (maneuverability), speed, handgrip strength and medicine ball throwing. All stages were performed in the afternoon, with an interval of 24 hours, being the first and second stages at the laboratory with controlled temperature and 
relative humidity $\left(24^{\circ} \mathrm{C}\right.$ and $44 \%$, respectively), and performance tests were performed on a basketball court similar to the training conditions of the athletes. In all situations, the subjects used their own sport wheelchair.

\section{Participants}

Participated in the present study 22 players, properly registered in the Federação Brasileira de Basquetebol em Cadeiras de Rodas (CBBC). All subjects had medical clearance to practice physical exercises. The descriptive data of the subjects are presented in Table 1 . Due to the absence of recent procedures of functional classification of the participants, this information was not used in this research. All in all, the athletes who participated in the study had paraplegia $(\mathrm{N}=4)$, poliomyelitis $(\mathrm{N}=9)$, amputation $(\mathrm{N}=3)$ and malformation in the lower body $(\mathrm{N}=6)$.

\section{Procedures}

Procedures to measure body composition and arm muscle area

Initially, it was collected the triceps, subscapular, abdominal and axillary skinfold thickness through a scientific caliper (Lange, USA). The values found are included in the equation proposed by Evans, Rowe, Misic, Prior, and Arngrimsson (2005), validated by Mojtahedi, Valentine, and Evans (2009) to determine the percent body fat:

$$
\mathrm{BF}(\%)=8.997+0.24658 \times(3 \mathrm{SKF})-6.343 \times(\text { gender })-1.998 \times(\text { race })
$$

Then they calculated the fat-free mass (FFM) and body fat $(\mathrm{BF})$, both in kilograms. The weight of the subjects was evaluated in a mechanical balance accurately 100g (FILIZOLA, BRA), with athletes out of wheelchairs and properly seated. The arm muscle area (AMA) was calculated using the model proposed by Frisancho (1981). For this measure relaxed and contracted right arm circumference were collected in centimeters, using a flexible fiber anthropometric tape (Mabbis, JAP) with a degree in millimeters. Subsequently, the triceps skinfold thickness was collected. All samples were taken in the right hemisphere of the participants, by a previously trained evaluator and using standardized measurement criteria (ISAK). After the collection of all points, the values were properly corrected for centimeters and substituted into the equation:

$$
\mathrm{AMA}=\frac{(\mathrm{AC}-\pi \times \mathrm{TS}) \times 2}{4 \times \pi}
$$

Where AMA is the arm muscle area with arm relaxed, AC (cm) is the arm circumference, TS $(\mathrm{cm})$ is the thickness of triceps skinfold thickness, and $\pi=3.1416$. The participants of this investigation presented no disabilities and improved arms perimeters.

\section{Test peak oxygen consumption $\left(\mathrm{VO}_{2 p e a k}\right)$}

The aerobic work capacity was verified by an incremental treadmill test, specially designed for wheelchair users (Imbramed, Wheelchair Series, BRA). Initially the subjects were positioned on the conveyor belt, and properly instructed regarding the security measures. At the distal end of the belt safety straps was placed a metal rod coated with a pad, to serve as a displacement limiter back of the sample. Then, the test began with a 5-minute warm up period, at a speed of 4 $\mathrm{km} / \mathrm{h}$. After this period, the protocol consisted of 1 -minute stages, increasing the speed by $1 \mathrm{~km} / \mathrm{h}$ each stage till subject exhaustion. At all times the gas exchange was measured using an open circuit spirometry system (COSMED, ITA), precalibrated according to the manufacturer's instructions. The criterion for determination of peak oxygen consumption $\left(\mathrm{VO}_{2 \text { peak }}\right)$ and respiratory decompensation point (ventilatory threshold or anaerobic threshold) was proposed by Wasserman, Hansen, Sue, Whipp, and Froelicher (1987), with the display of the inflection curve of oxygen consumption and dioxide carbon production. In addition to the voluntary withdrawal of the subjects, the test was interrupted when a heart rate of approximately $95 \%$ of maximum predicted for age, and a respiratory quotient equal to or greater than 1 was achieved. 


\section{Wingate anaerobic test}

For verification of the maximum anaerobic power a Wingate test in an arm ergometer with mechanical braking (CEFISE, BRA) was used. Initially, the subjects were placed on the ergometer by a regulator according to their anthropometric characteristics. Then, the subjects underwent a 5-minute warm-up period in the equipment itself, without the use of braking loads. After this period, the participants were instructed to develop the maximum possible speed in a period of 10 seconds. Immediately after this period a corresponding braking load to $5 \%$ of the body weight of the subject was placed, and the subjects were instructed to maintain the same speed for a period of 30 seconds. In the meantime, the number of rotations was measured by inductive sensor (Sensorbras, BRA) every 5 seconds, and transmitted to the computer. The maximum and mean power was calculated (POMÁX and POMED, respectively) and the percentage of fatigue index (FI\%), based on the relationship between the number of revolutions (RPM), and the braking load supported during 30 seconds.

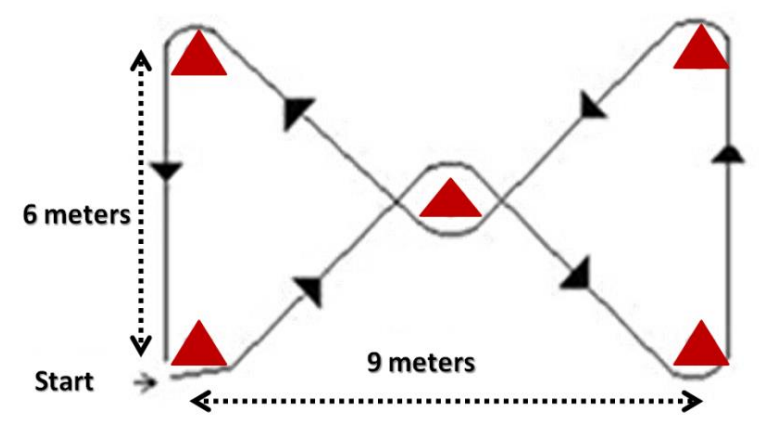

Figure 1. Rectangular (6x9 meters) agility test skematic. Adapted from Gorgatti and Bohme (2006).

\section{Rectangular Agility test}

To evaluate the agility it was used a test proposed by Gorgatti and Bohme (2006). Five cones were distributed on the court in a rectangle 6 feet wide by 9 meters long. A cone is positioned in the center of the rectangle to serve as a cone maneuver. The subjects were instructed to roam, zig zag, the course marked by cones in the shortest time possible. A previously trained investigator was positioned in the cone of start/finish, activating the timer to the first movement and stopping when the subjects fully surpassed the finish line. The procedure was repeated twice, with the shortest time between attempts to measure agility. Figure 1 illustrates organized route.

\section{Sprint test of 30 meters (30 m-sprint)}

The speed test at 30 meters (Gaya \& Silva, 2007), was used to evaluate the rapid straight deployment capacity. A course measured on the sidelines of the playing court was used as reference. Two cones are positioned at the ends to signal the start and end of test. A third cone was placed 5 meters after the finish line, and the participants were instructed to patrol the distance to the third cone at the highest possible speed without deviate from the route. This was necessary to prevent the subjects deceleration before arriving at the last cone. An evaluator was positioned in the cone of arrival, and controlled the output (in the first movement) and the arrival (when exceeded the line demarcated by the cone) of the participants. The procedure was repeated twice, and it was considered the shortest time between attempts.

\section{The medicine ball throwing test}

Originally described by Marins and Giannichi (1996), the throwing of medicine ball test was used to evaluate the power of the upper limbs. Sitting in their one wheelchair subjects were instructed to throw one $2 \mathrm{~kg}$ medicine ball as far as possible. Participants had their wheelchairs positioned on a side wall of the court to prevent back displacement. One investigator was positioned on the back of the wheelchair to prevent subjects movements and help to execute the movement with the trunk pitch. A second evaluator was positioned in order to check the exact location where the ball touched the ground. In two attempts, it was considered the longest distance.

\section{Handgrip dynamometry}

The subjects were comfortably seated. Then, with the arm and forearm forming an angle of $90^{\circ}$, the participants had the manual dynamometer (Jamar, JAP) adjusted to the size of their hands. At the signal of evaluators subjects performed the 
clamping motion with their hands, using the maximum isometric strength as possible for 5 seconds. The same procedure was repeated 2 times in each hand alternately. The highest value in kilogram-force reached was considered.

\section{Statistical analysis}

Previously, an exploratory analysis of data was performed in order to verify the assumptions of normality using the Shapiro-Wilk test. Then the measures of central tendency and normality were analyzed by mean and the respective standard deviations of all variables. Given that, all parametric data were considered to verify the relationship between the AMA, BF and FFM with the various physical fitness variables, and Pearson product-moment correlation coefficient was calculated.
Then to determine the relative contribution of the AMA, BF and FFM on athletic performance, it was used a simple linear regression analysis for those variables considered significantly associated with $p \leq 0.05$. An isolated mathematical model for each performance variable was created and the wire prediction level checked by the value of the determination coefficient $\left(R^{2}\right)$ and their respective statistical significance. Data were tabulated and calculated using the Graphpad Prism (Version 5.0, GraphPad, USA). For all analyzes, it was considered a significance level of $p \leq .05$.

\section{RESULTS}

In Table 1 descriptive data is presented. Correlation between AMA and athletic performance variables are shown in Figure 2.

Table 1

Descriptive data of the subjects and variables $(N=22)$

\begin{tabular}{lccc}
\hline Variables & Average \pm SD & Maximum & Minimum \\
\hline Age (years) & $22.5 \pm 5.3$ & 38.00 & 15.00 \\
Weight $(\mathrm{kg})$ & $56.9 \pm 12.6$ & 97.40 & 37.30 \\
Body fat (\%) & $10.92 \pm 3.66$ & 18.16 & 5,46 \\
Body fat (kg) & $6.50 \pm 3.53$ & 17.45 & 2.04 \\
Fat free mass (kg) & $50.41 \pm 9.58$ & 79.95 & 35.26 \\
Arm muscle area $\left(\mathrm{cm}^{2}\right)$ & $27.9 \pm 3.4$ & 35.70 & 22.70 \\
Right handgrip $(\mathrm{kgf})$ & $45.7 \pm 11.0$ & 66.00 & 12.00 \\
Left handgrip (kgf) & $45.1 \pm 7.1$ & 59.00 & 32.00 \\
Peak oxygen consumption $\left(\mathrm{ml} / \mathrm{kg} / \mathrm{min}^{-1}\right)$ & $44.7 \pm 7.9$ & 61.33 & 33.25 \\
Oxygen consumption at the threshold $\left(\mathrm{ml} / \mathrm{kg} / \mathrm{min}^{-1}\right)$ & $32.4 \pm 5.4$ & 42.33 & 24.14 \\
Agility (s) & $16.4 \pm 0.8$ & 17.69 & 14.40 \\
Medicine ball throwing (m) & $6.35 \pm 1.3$ & 9.50 & 4.20 \\
Absolute anaerobic power $(\mathrm{W})$ & $438.4 \pm 160.3$ & 866.65 & 271.86 \\
Relative anaerobic power $(\mathrm{W} / \mathrm{kg})$ & $245.4 \pm 87.6$ & 479.12 & 106.39 \\
Sprint test-30 meters $(\mathrm{s})$ & $5.3 \pm 0.5$ & 6.35 & 4.35 \\
\hline
\end{tabular}

Relationships between body composition and arm muscle area with athletic performance

Analyzing the Pearson correlation coefficients (Figure 2), positive relationships are found between the AMA and the handgrip $(r=.36 ; p=$ .08; panel $A)$, peak oxygen consumption $(r=.59$; $p=.035)$ and threshold $(r=.27 ; p=.20$; panel $B)$, medicine ball throwing $(r=.54 ; \mathrm{p}=.008$; panel D) and absolute $(r=.61 ; p=.002)$ and relative anaerobic power $(r=.67 ; \mathrm{p}=.0005$; panel $\mathrm{E})$. For agility and speed tests correlations are negative $(\mathrm{r}=-.12 ; \mathrm{p}=.16$; panel $\mathrm{C}$ and $\mathrm{r}=-.24 ; \mathrm{p}=.27$; panel $\mathrm{F}$, respectively), indicating inversely proportional relationship. However, only oxygen consumption, anaerobic power and throwing medicine ball, showed statistically significant values $(P<.05)$. 
A



C

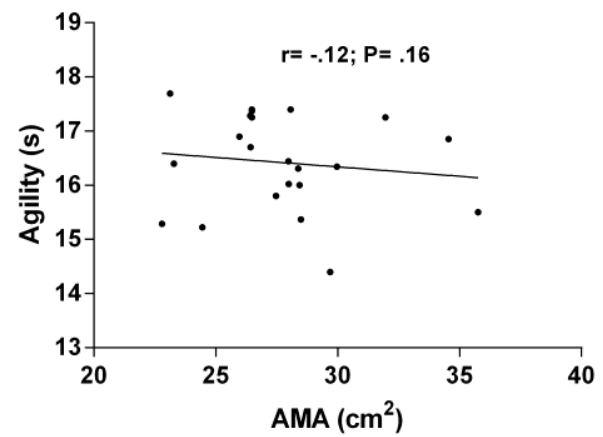

E

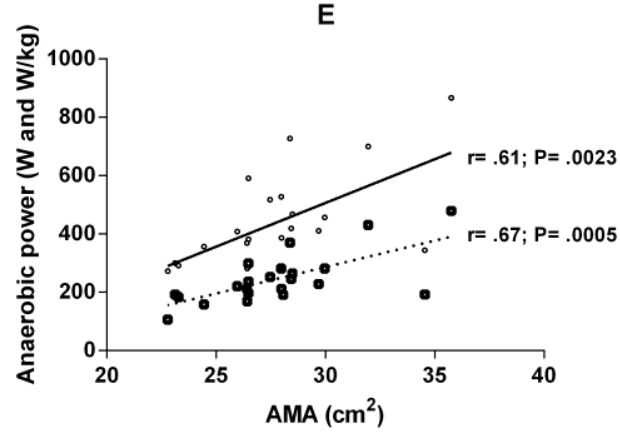

B

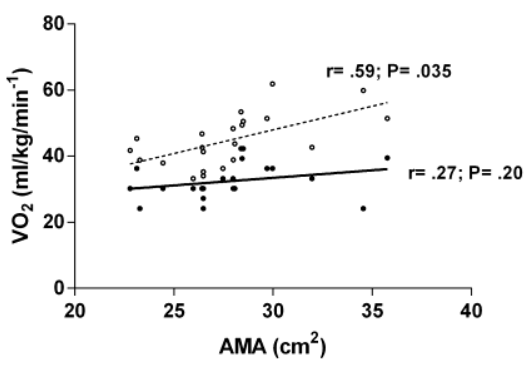

D

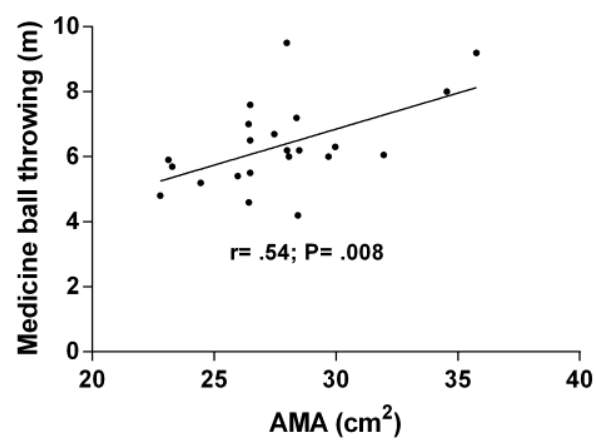

$\mathbf{F}$

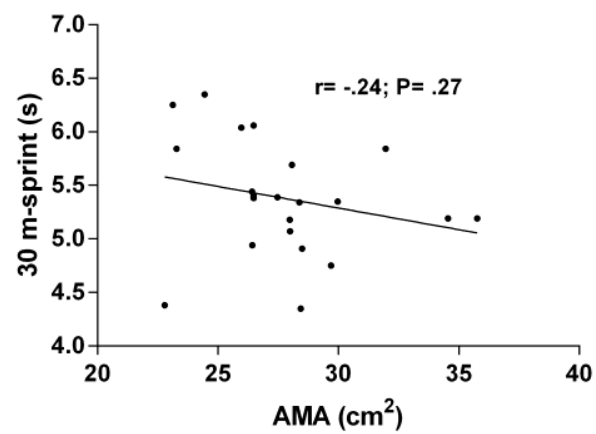

Figure 2. Values of correlation Pearson product-moment between the arm muscle area (AMA) and all variables of athletic performance; Relationship between AMA and isometric handgrip strength; (Panel A, dashed lines represent isometric strength of the right hand); Relationship between AMA and oxygen consumption (Panel B, dashed lines represent the peak oxygen consumption); Relationship between AMA and rectangular agility test (Panel C); Relationship between AMA and medicine ball throwing (Panel D); Relationship between AMA and anaerobic power (Panel E, dashed lines represent the relative anaerobic power); Relationship between AMA and 30 m-sprint (Panel F); r=Pearson correlation moment-product.

In figure 3 the values of correlation between the fat mass and athletic performance variables are presented. Significant associations were found with isometric force of the left hand $(r=$ $.43, \mathrm{p}=.038$; panel $\mathrm{A})$, medicine ball throwing $(\mathrm{r}=.50, \mathrm{p}=.014 ;$ panel $\mathrm{D})$ and absolute anaerobic power $(\mathrm{r}=.77, \mathrm{p}=0.000)$ and relative $(\mathrm{r}=.82, \mathrm{p}=.000)$, both in the panel E. Regarding the other variables, weak relationships were checked with the agility $(r=.16 ; \mathrm{p}=.451$, panel $\mathrm{C})$, with time $30 \mathrm{~m}$-sprint $(\mathrm{r}=.29, \mathrm{p}=.169 ; \mathrm{F}$ panel) and oxygen consumption threshold $(\mathrm{r}=$ $.24, \mathrm{p}=.254$; panel B). From the peak oxygen consumption, fat mass was negatively and weakly correlated $(r=-.00, p=.995$; panel B). 
A

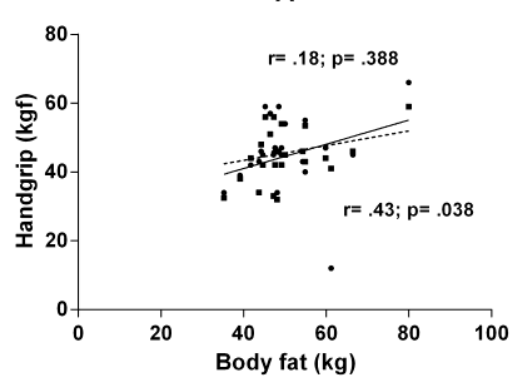

C

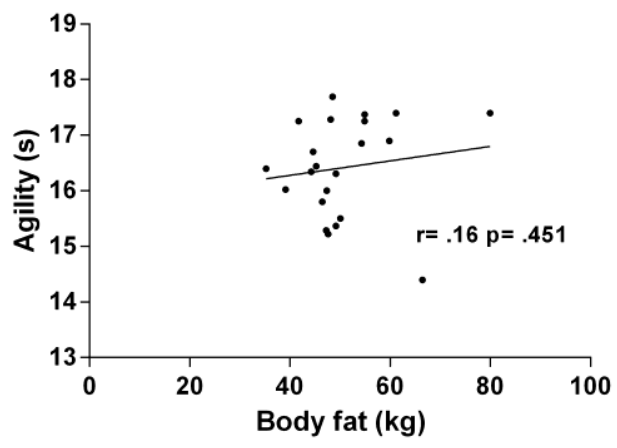

E

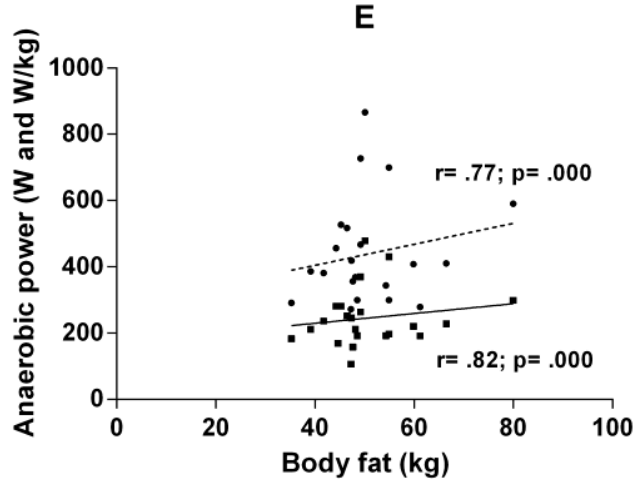

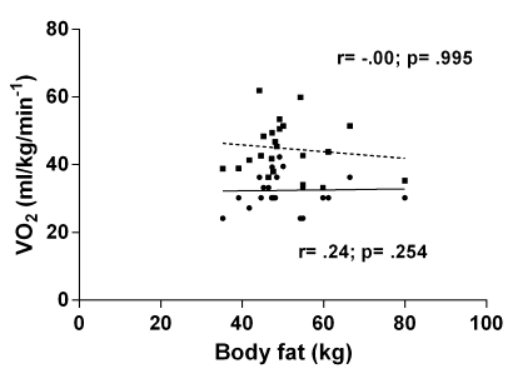

D

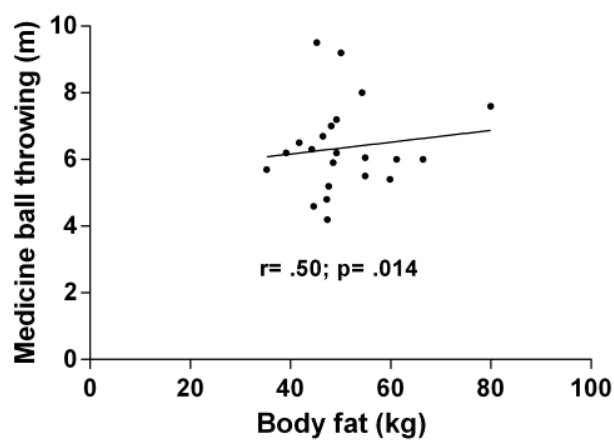

$\mathbf{F}$

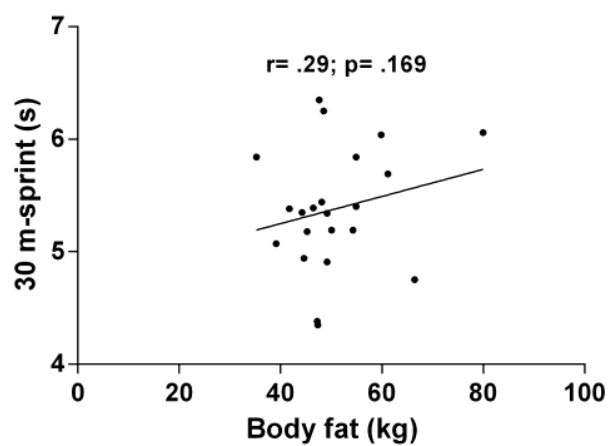

Figure 3. Values of correlation Pearson product-moment between the body fat (BF) and all variables of athletic performance; Relationship between BF and isometric handgrip strength; (Panel A, (Panel A, dashed lines represent isometric strength of the right hand); Relationship between BF and oxygen consumption (Panel B, dashed lines represent the peak oxygen consumption); Relationship between BF and rectangular agility test (Panel C); Relationship between BF and medicine ball throwing (Panel D); Relationship between BF and anaerobic power (Panel E, dashed lines represent the absolute anaerobic power); Relationship between BF and 30m-sprint (Panel F); $r=$ Pearson correlation moment-product.

Regarding the fat free mass, figure 4 shows the correlation values with all the athletic performance variables. Positive and significant correlations were found with the isometric force of the left hand $(r=.44, p=.032$; panel $A)$, throwing medicine ball $(\mathrm{r}=.43, \mathrm{p}=.039$; panel $\mathrm{D})$, and the absolute $(\mathrm{r}=.64 ; \mathrm{p}=.000)$ and relative aerobic power $(r=.69 ; p=.000)$, both can be viewed in panel E. There were positive and weak correlation to the isometric strength of his right hand $(\mathrm{r}=.03 ; \mathrm{p}=.872$; panel $\mathrm{A})$, the oxygen consumption threshold $(r=.003 ; p=.872)$ and peak $(r=.22 ; p=.311$; panel $B)$, the agility $(r=$ $.09 ; \mathrm{p}=.651$; panel $\mathrm{C}$ ) and the time in the $30 \mathrm{~m}$ sprint $(r=.26 ; p=.222$; panel $D)$. 
A

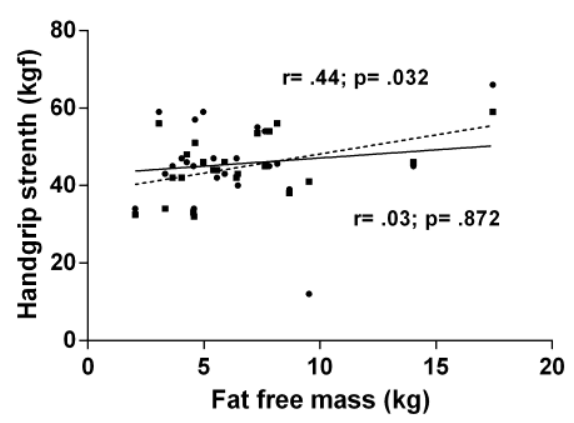

C

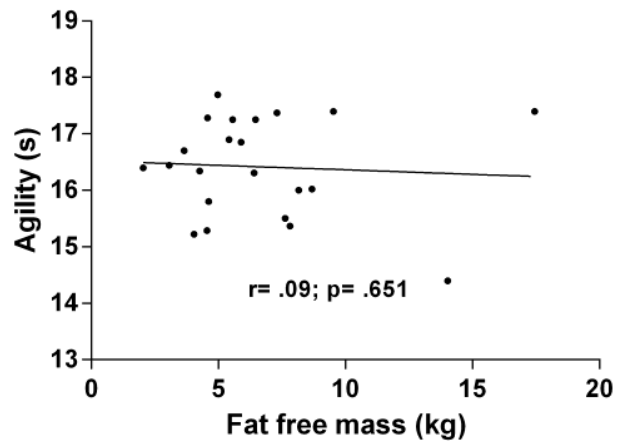

E

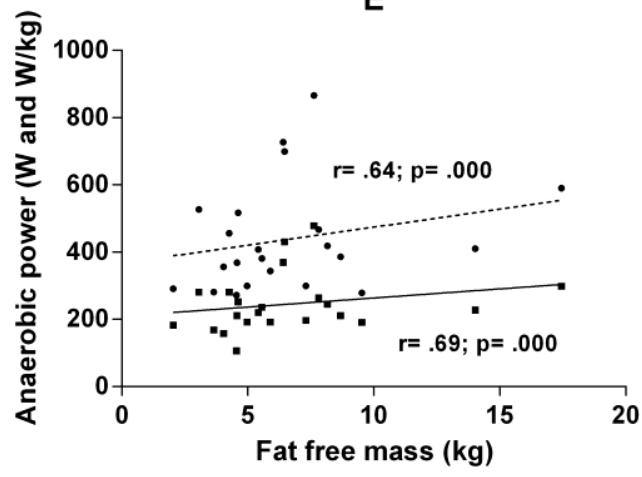

B

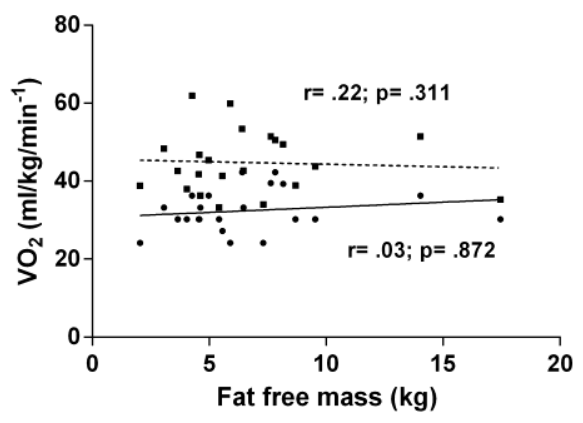

D

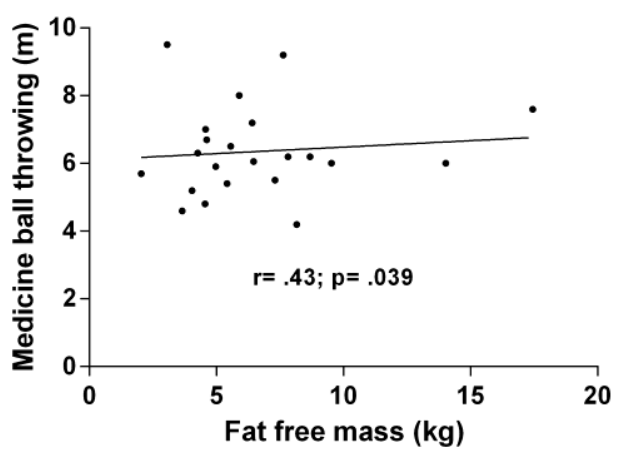

$\mathbf{F}$

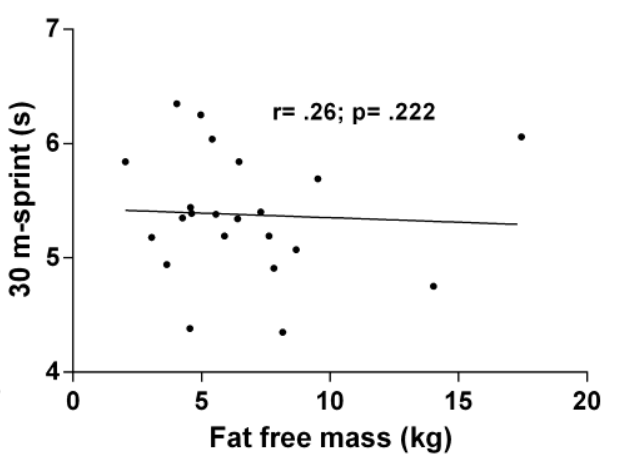

Figure 4. Values of correlation Pearson product-moment between the fat free mass (FFM) and all variables of athletic performance; Relationship between FFM and isometric handgrip strength. (Panel A, dashed lines represent isometric strength of the left hand); Relationship between FFM and oxygen consumption (Panel B, dashed lines represent the peak oxygen consumption); Relationship between FFM and rectangular agility test (Panel C); Relationship between FFM and medicine ball throwing (Panel D); Relationship between FFM and anaerobic power (Panel E, dashed lines represent the absolute anaerobic power); Relationship between FFM and 30m-sprint (Panel $\mathrm{F}) ; \mathrm{r}=$ Pearson correlation moment-product.

\section{Contributions of the arm muscle area and body composition for athletic performance}

All explanatory mathematical models for each dependent variable (athletic performance) and independent (AMA, BF and FFM) was presented in table 2. After mathematical modeling using simple linear regression between $\mathrm{AMB}$ and $\mathrm{VO}_{2 \text { peak, }}$ POMÁX, POMED and MB, all developed models were statistically valuable when comparing the actual values and those estimated by the model $(p<.05)$. In addition, predictive models based on AMB showed determination coefficient values $\left(\mathrm{R}^{2}\right)$ greater than $20 \%$, to .35 (35\%) for $\mathrm{VO}_{2 \text { peak }} ; .37$ (37\%) for POABS and 0.46 $(46 \%)$ for POREL; and .29 (29\%) for the medicine ball throwing.

For the prediction model taken from body fat, only the left hand isometric strength showed significant results for the coefficient of determination $\left(\mathrm{R}^{2}=.18, \mathrm{p}=.038\right)$, explaining 
about $18 \%$ of the variation observed in isometric strength. The determination coefficient to medicine ball throwing was .01 (.1\%), the absolute power $.03(.3 \%)$ and the relative power of .02 (.2\%). For these predictive models (medicine ball and anaerobic power), based on body fat, values were not found significant.

Similarly, with respect to fat free mass, only the left hand isometric strength showed significant results for the determination coefficient $\left(\mathrm{R}^{2}=.20, \mathrm{p}=.32\right)$, explaining about $20 \%$ of the observed variation in isometric strength. For the medicine ball throwing the determination coefficient values were $.01(.1 \%)$, the absolute power $.05(.5 \%)$ and the relative power $.04(.4 \%)$, each with no significant values $(\mathrm{p}<.05)$.

Table 2

Regression models and their respective values of the coefficient of determination between the arm muscle area (AMA), body fat $(B F)$ and fat free mass (FFM) to all variables of athletic performance of wheelchair basketball players $(n=22)$

\begin{tabular}{llc} 
Prediction models for athletic performance using AMA & $\mathrm{R}^{2}$ & $p$ \\
\hline $\mathrm{VO}_{2 \text { peak }}\left(\mathrm{ml} / \mathrm{kg} / \mathrm{min}^{-1}\right): 1.430 \times\left(\mathrm{AMA}, \mathrm{cm}^{2}\right)+5.088$ & .35 & .003 \\
Medicine ball throwing $(\mathrm{m}): 0.2218 \times\left(\mathrm{AMA}, \mathrm{cm}^{2}\right)+0.1955$ & .29 & .008 \\
POABS $(\mathrm{W}): 29.98 \times\left(\mathrm{AMA}, \mathrm{cm}^{2}\right)-393.6$ & .37 & .002 \\
POREL $(\mathrm{W} / \mathrm{kg}): 18.12 \times\left(\mathrm{AMA}, \mathrm{cm}^{2}\right)-257.4$ & .46 & .000
\end{tabular}

Prediction models for athletic performance using BF

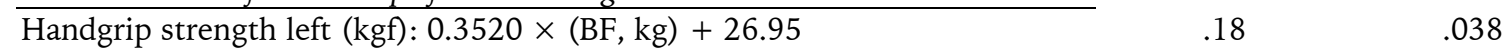

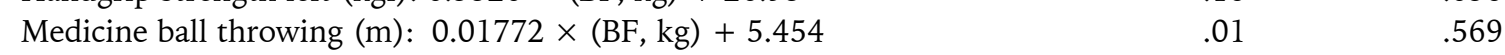

POABS $(\mathrm{W}): 3.171 \times(\mathrm{BF}, \mathrm{kg})+277.7 \quad 03 \quad .392$

POREL $(\mathrm{W} / \mathrm{kg}): 1.476 \times(\mathrm{BF}, \mathrm{kg})+170.5 \quad .02 \quad .467$

Prediction models for athletic performance using FFM

Handgrip strength left (kgf): $0.9859 \times($ FFM, kg) $+38.29 \quad 032.20 \quad .032$

Medicine ball throwing $(\mathrm{m}): 0.03805 \times(\mathrm{FFM}, \mathrm{kg})+6.100 \quad .01 \quad .204$



POREL $(\mathrm{W} / \mathrm{kg}): 5.402 \times(\mathrm{FFM}, \mathrm{kg})+209.5$

$.04 \quad .329$

Note. VO2peak: peak oxygen consumption; POABS: absolute anaerobic power; POREL: relative anaerobic power; $\mathrm{R} 2$ : determination coefficient.

\section{DISCUSSION}

The objectives of this study were a) to determine the relationship between the composition and the muscular area of the arm with athletic performance in wheelchair basketball players; and b) check the level of dependency between these variables in the group of athletes. Thus, the main result of this study was to analyze objectively the importance of fat free mass, body fat, the arm muscular area, and the relationship with the performance in wheelchair basketball players.

Among the analyzed variables, oxygen consumption, dynamic muscle strength (represented by the distance of the medicine ball throwing) and isometric (handgrip) strength beyond the anaerobic power, were those that were more related and might have predicted performance more efficiently than the body composition and the arm muscle area. To date there have been no studies conducted for this purpose, probably due to lack of standardized anthropometric methods in addition to the variety of procedures for conditioning tests for this audience.

\section{Relationship between the variables}

In this sense, Ozmen, Yuktasir, Yildirim, Yalcin, and Willems (2014) reported that the strength and power are key variables in wheelchair basketball, for the case of a sport that requires certain specific movements (e.g. free throw, dribbling and wheelchair propulsion) muscle strength and physical fitness must be estimated for these athletes. Although there are no validated methods for assessing body composition in athletes with disabilities, Mojtahedi, Valentine, and Evans (2009), in their study of athletes with spinal cord injury, suggested that body composition data are 
important in monitoring training programs resulting in an improved performance of the athlete. In this sense, it is recommended, where possible, the use of more robust methods for assessing body composition, such as DEXA (Dual Energy X-Ray), or ultrasound.

We know that the evaluation of oxygen consumption is an excellent predictor for analyzing body composition of any individual, whether spinal cord injured, either individuals without injury. However, $\mathrm{VO}_{2} \max$ is a commonly used index and used to evaluate the level of cardiorespiratory fitness of individuals, being considered the best indicator of the cardiorespiratory system and aerobic fitness. Flores, de Campos, Gouveia, de Souza Pena, and Gorla (2013) stated that the $\mathrm{VO}_{2 \max }$ is the best marker for the functional capacity of individuals. Therefore, the greater the fitness of the individual (lean body mass) higher his $\mathrm{VO}_{2}$.

The arm muscle area is an important predictor of performance in individual sports such as swimming (Santos et al., 2014). This study also showed that the amount of muscle is presented as a control factor or high associative strength also in athletes with a physical disability. Most of associations found through the Pearson correlation coefficients showed that maintaining optimal levels of muscular cross section in the upper limbs promotes better results on standardized tests, including those not directly related to the body composition, such as maximum oxygen consumption.

The metabolic capacity, in particular can be explained by the different phases of oxygen consumption (Denadai, 1995). Some of these steps include the use of oxygen as an energy source, and thus a greater muscle contribution, adduced by higher enzymatic components and local energy substrates, could influence the momentary income gains in a standardized exercise test (Vanlandewijck, Daly, \& Theisen, 1999; Vanlandewijck, van de Vliet, Verellen, \& Theisen, 2006).

There were also positive and significant correlations between AMA and Wintage test parameters. This capability, in particular is extremely dependent on the number of metabolically active tissue component, as well as substrate to withstand stress by the predetermined time (30 seconds). A prominent factor in this regard is that both power variables, both the relative and absolute, showed to be significant. In this regard, although we had different disabilities in the team (spina bifida, spinal cord injury-rachis, polio, amputations, etc.), muscle cross-sectional area appears to have an important influence on the physical performance of athletes.

This research showed that the arm muscle area, body fat and fat free mass were correlated and showed significant prediction levels in relation to isometric strength of the right and left hands. To date there is no data in the literature that can support these findings in samples of athletes with physical disabilities. Thus Miller (2002) stated that the biomechanical characteristics of the pitch in the top level basketball athletes can be described with the elevation of the ball beyond the face in the position where the movement is completed with the extension of the right elbow and flexion of wrist and fingers. Regardless of the dominant hand, a player with good technical level should display such characteristics.

Thus, contrasting with throwing arm, the opposite one should serve as support and guidance to the basket, performing an important contraction (often isometric) to control the technical gesture. In addition to this technical aspect, some gaming action can also occur in slow contraction speed conditions, or even isometric such that the ball disputes, blocks and rebounds near basket (Wang, Chen, Limroongreungrat, \& Change, 2005). Nevertheless, this study showed that the dependence of the isometric strength levels for muscularity indicators and body composition were not considered significant.

\section{Level of dependency between the variables}

Among the predictive mathematical models found in this study, those with the best determination coefficient, and consequently the greater explanatory power for athletic performance were those that predicted peak oxygen consumption (35\% explanatory power) and power absolute anaerobic $(37 \%$ of explanatory power) and relative $(46 \%$ 
explanatory power), all obtained through the arm muscle area. The other models derived from the fat mass and fat-free mass did not show determination coefficient $\left(\mathrm{R}^{2}\right)$ greater than .20 , values related to explanatory powers of up to $20 \%$ of the variance explained by the model.

Some factors could be contributing to these findings. Initially, the method used in this study to determine the arm muscle area considers only the morphological dimensions of the upper limbs, regardless of the subject analysis (Serpa, Nogueira, \& Pompeu, 2014). Thus, becomes an index accepted for control of the training or even the nutritional level of athletes with some kind of physical disabilities, especially those who have the ends of the upper limbs preserved.

This same characteristic does not occur with the estimated equations for determining the body composition (body fat and fat free mass), as is the case of the model chosen in this study, which are used in this population. Commonly equations are proposed for athletes and sedentary subjects without shortcomings and then validated according to the characteristics of a given population. This implementation may lead to estimation errors due to expected changes in the distribution of body components (fat, skeletal muscle, bone and water) in some types of common disorders such as quadriplegia, paraplegia, and poliomyelitis (Cimigliaro et al, 2013).

In general, it is noticed that the arm muscle area accounts for $46 \%$ of income in relative anaerobic power, $37 \%$ in absolute anaerobic power and $35 \%$ in oxygen consumption. These findings show the relative importance of morphology in the metabolic athletic performance in basketball players in wheelchairs. Other factors such as the time of practice, individual skill, economy of movement and the level of training, may be contributing to the athletic performance in specific ways in each of the dimensions analyzed.

In our understanding, this study points out important indicators when dealing with wheelchair basketball players. The use of the upper limbs while shifting the drivers in wheelchairs, both to perform specific actions play (offense and defense), and to perform motor tasks with aerobic and anaerobic characteristics, as pointed out in previous studies (Molik et al., 2008; Pérez-Tejero \& Pinilla Arbex, 2015).

An additional concern in the context of sports for people with disabilities, especially at higher levels of performance, is the consideration of a simple and low-cost measure that could serve as a parameter of training control during the season. This becomes of paramount importance for coaches, physiologists and players, increasing the assessment of physical performance of athletes in this population.

The main limitation of the study was the nonutilization of the functional classification of the evaluated athletes. However, considering outdated values of functionality could influence negatively the results found. In this regard, it is recommended that further studies must be conducted controlling possible influencing variables in each of these physiological aspects. An important recommendation is to consider the functional classification system developed for wheelchair basketball or other type of disability. Finally, another limitation was the use of standard methods for assessing body composition of wheelchair athletes. Still, there are no low cost validated methods for such analysis in this population.

\section{CONCLUSION}

In view of the results presented, we concluded that there is significant influence of lean mass, particularly skeletal muscle tissue in the upper limbs or arm muscular area, in athletic performance of wheelchair basketball players. With this, assessment, training and control of body composition in athletes with disabilities constitute important parameters for athletic performance in wheelchair court sports such as wheelchair basketball.

\section{Acknowledgments:}

We would like to thank the technical support offered by Marcus Plautu and Tatiana Acioly in the Human Performance Laboratory for valuable assistance during the phases of research, especially with regard data collection. 
Conflict of interest:

Nothing to declare.

\section{Funding:}

The materials used in the study were provided by the University of Pernambuco, and the financial support kindly provided by the Brazilian Government through the Ministry of Sports

\section{REFERENCES}

Barfield, J. P., \& Malone, L. (2012). Performance Test Differences and Paralympic Team Selection: Pilot Study of the United States National Wheelchair Rugby Team. International Journal of Sports Science and Coaching, 7(4), 715-720. Doi: 10.1260/17479541.7.4.715

Cirnigliaro, C. M., La Fountaine, M. F., Emmons, R., Kirshblum, S. C., Asselin, P., Spungen, A. M., \& Bauman, W. A. (2013). Prediction of limb lean tissue mass from bioimpedance spectroscopy in persons with chronic spinal cord injury. The Journal of Spinal Cord Medicine, 36(5), 443-453. https://doi.org/10.1179/2045772313Y.0000000 108

Davis, G. M., \& Shephard, R. J. (1990). Strength training for wheelchair users. British journal of sports medicine, 24(1), 25-30. Doi:10.1136/bjsm.24.1.25

Denadai, B. S. (1995). Consumo máximo de oxigênio: fatores determinantes e limitantes. Revista Brasileira de Atividade Física \& Saúde, 1 (1), 85-94. Drolet, M., Noreau, L., Vachon, J., \& Moffet, H. (1999). Muscle strength changes as measured by dynamometry following functional rehabilitation in individuals with spinal cord injury. Archives of Physical Medicine and Rehabilitation, 80(7), 791800.

Evans, E. M., Rowe, D. A., Misic, M. M., Prior, B. M., \& Arngrimsson, S. A. (2005). Skinfold prediction equation for athletes developed using a fourcomponent model. Medicine and science in sports and exercise, $37(11), \quad 2006.2$ Doi: 10.1249/01.mss.0000176682.54071.5c

Flores, L. A., de Campos, L. F. C. C., Gouveia, R. B., de Souza Pena, L. G., \& Gorla, J. I. (2013). Avaliação da potência aeróbia de praticantes de Rugby em Cadeira de Rodas através de um teste de quadra. Motriz, 19(2), 368-377.

Frisancho, A. R. (1981). New norms of upper limb fat and muscle areas for assessment of nutritional status. The American journal of clinical nutrition, 34(11), 2540-2545.

Gaya, A., \& Silva, G. (2007). Manual de aplicação de medidas e testes, normas e critérios de avaliação. Projeto Esporte Brasil, 1-27.

Goosey-Tolfrey, V. (2010). Supporting the paralympic athlete: focus on wheeled sports. Disability and rehabilitation, 32(26), 2237-2243. Doi: $10.3109 / 09638288.2010 .491577$
Goosey-Tolfrey, V. (2005). Physiological profiles of elite wheelchair basketball players in preparation for the 2000 Paralympic Games. Adapted Physical Activity Quarterly, 22(1), 57-66.

Goosey-Tolfrey, V., \& Leicht, C. A. (2013). Field-based physiological testing of wheelchair athletes. Sports medicine, 43(2), 77-91. Doi: 10.1007/s40279-012-0009-6

Goosey-Tolfrey, V. L., \& Tolfrey, K. (2008). The multistage fitness test as a predictor of endurance fitness in wheelchair athletes. Journal of sports sciences, 26(5), 511-517. Doi: http://dx.doi.org/10.1080/02640410701624531

Gorgatti, M. G., \& Böhme, M. T. S. (2003). Autenticidade científica de um teste de agilidade para indivíduos em cadeira de rodas. Revista Paulista de Educação Física, 17(1), 41-50.

Granados, C., Yanci, J., Badiola, A., Iturricastillo, A., Otero, M., Olasagasti, J., ... Gil, S. M. (2015). Anthropometry and Performance in Wheelchair Basketball. Journal of Strength and Conditioning Research, 29(7), 1812-1820. https://doi.org/10.1519/JSC.000000000000081 7

Gil, S. M. (2015). Anthropometry and performance in wheelchair basketball. The Journal of Strength $\mathcal{E}$ Conditioning Research, 29(7), 1812-1820. Doi: 10.1519/JSC.0000000000000817

Santos, M. A. M., Junior, M. L. B., de Castro Melo, W. V., da Costa, A. V., \& Costa, M. da C. (2012). Estimate of propulsive force in front crawl swimming in young athletes. Open Access Journal of Sports Medicine, 3, 115-120. https://doi.org/10.2147/OAJSM.S35430

Laferrier, J. Z., Rice, I., Pearlman, J., Sporner, M. L., Cooper, R., Liu, T., \& Cooper, R. A. (2012). Technology to improve sports performance in wheelchair sports. Sports Technology, 5(1-2), 4-19. Doi: 10.1080/19346182.2012.663531

Marins, J. C. B., \& Giannichi, R. S. (1998). Avaliação e prescrição de atividade física: guia prático. Shape.

Mello, M. T., \& Winckler C. (2012). Esporte paralímpico. São Paulo: Atheneu.

Miller, S. A. (2002). Variability in basketball shooting: practical implications. International research in sports biomechanics, 27-34.

Mojtahedi, M. C., Valentine, R. J., \& Evans, E. M. (2009). Body composition assessment in athletes with spinal cord injury: comparison of field methods with dual-energy X-ray absorptiometry. Spinal Cord, 47(9), 698-704. Doi: $10.1038 /$ sc. 2009.20

Molik, B., Lubelska, E., Kosmol, A., Bogdan, M., Yilla, A., \& Hyla, E. (2008). An examination of the international wheelchair rugby federation classification system utilizing parameters of offensive game efficiency. Adapted Physical Activity Quarterly, 25(4), 335-351.

Molik, B., Laskin, J. J., Kosmol, A., Marszałek, J., Morgulec-Adamowicz, N., \& Frick, T. (2014). Relationships between anaerobic performance, field tests, and functional level of elite female 
wheelchair basketball athletes. Human Movement, 14(4), 366-371. https://doi.org/10.2478/humo2013-0045

Molik, B., Laskin, J. J., Kosmol, A., Skucas, K., \& Bida, U. (2010). Relationship between functional classification levels and anaerobic performance of wheelchair basketball athletes. Research Quarterly for Exercise and Sport, 81(1), 69-73. https://doi.org/10.1080/02701367.2010.105996 29

Moura, T., Costa, M., Oliveira, S., Júnior, M. B., RittiDias, R., \& Santos, M. (2014). Height and body composition determine arm propulsive force in youth swimmers independent of a maturation stage. Journal of Human Kinetics, 42, 277-284. https://doi.org/10.2478/hukin-2014-0081

Neto, F. R., \& Lopes, G. H. (2011). Body composition modifications in people with chronic spinal cord injury after supervised physical activity. The journal of spinal cord medicine, 34(6), 586-593. Doi: 10.1179/2045772311Y.0000000038

Noreau, L., Shephard, R. J., Simard, C., Paré, G., \& Pomerleau, P. (1993). Relationship of impairment and functional ability to habitual activity and fitness following spinal cord injury. International Journal of Rehabilitation Research, 16(4), 265-276.

Ozmen, T., Yuktasir, B., Yildirim, N. U., Yalcin, B., \& Willems, M. E. (2014). Explosive strength training improves speed and agility in wheelchair basketball athletes. Revista Brasileira de Medicina do Esporte, 20(2), 97-100. Doi: 10.1590/151786922014200201568

Pérez-Tejero, J., \& Arbex, J. P. (2015). Rendimiento del jugador de baloncesto en silla de ruedas según la estadística de juego. Cuadernos de Psicología del Deporte, 15(3), 231-236.

Rhodes, J. M., Mason, B. S., Malone, L. A., \& GooseyTolfrey, V. L. (2015). Effect of team rank and player classification on activity profiles of elite wheelchair rugby players. Journal of sports sciences, 33(19), 2070-2078. Doi: 10.1080/02640414.2015.1028087

Santos, D. A., Dawson, J. A., Matias, C. N., Rocha, P. M., Minderico, C. S., Allison, D. B., ... Silva, A. M. (2014). Reference values for body composition and anthropometric measurements in athletes. Plos One, 9(5), e97846. https://doi.org/10.1371/journal.pone.0097846

Serpa, T. K. F., Nogueira, F. D. S., \& Pompeu, F. A. M. S. (2014). Prediction of lean body mass in Brazilian adults through arm muscle area. Revista Brasileira de Medicina do Esporte, 20(3), 186-189. Doi: 10.1590/1517-86922014200301839

Thomas, J. R., Nelson, J. K., \& Silverman, S. J. (2002). Métodos de pesquisa em atividade física. Porto Alegre: Artmed.

Vanlandewijck, Y. C., Van De Vliet, P., Verellen, J., \& Theisen, D. (2006). Determinants of shuttle run performance in the prediction of peak $\mathrm{VO} 2$ in wheelchair users. Disability and rehabilitation, 28(20), 1259-1266. Doi: 10.1080/09638280600554769

Vanlandewijck, Y. C., Daly, D. J., \& Theisen, D. M. (1999). Field test evaluation of aerobic, anaerobic, and wheelchair basketball skill performances. International journal of sports medicine, 20(8), 548-554.

Wang, Y. T., Chen, S. Limroongreungrat, W. T., \& Change, L. S. (2005). Contributions of selected fundamental factors to wheelchair basketball performance. Medicine and science in sports and exercise, 37(1), 130-137. Doi: 10.1249/01.MSS.0000150076.36706.B2

Wasserman, K., Hansen, J. E., Sue, D. Y., Whipp, B. J., \& Froelicher, V. F. (1987). Principles of exercise testing and interpretation. Journal of Cardiopulmonary Rehabilitation and Prevention, 7(4), 189. 